\title{
GENOTYPE BY ENVIRONMENT INTERACTION EFFECTS ON PLANT HEIGHT OF WHEAT GENOTYPES CARRYING RHT 8 DWARFING GENE
}

\author{
Yuksel KAYA ${ }^{1, *}$, Alexey I. MORGOUNOV ${ }^{2}$, Mesut KESER ${ }^{3}$ \\ ${ }^{1}$ Bahri Dagdas International Agricultural Research Institute, Konya, TURKEY \\ ${ }^{2}$ CIMMYT, P.K. 39 Emek, Ankara, Turkey \\ ${ }^{3}$ ICARDA, P.K. 39 Emek, Ankara, Turkey \\ *Corresponding author: yuksel_k@yahoo.com
}

Received: 29.01.2015

\begin{abstract}
Twenty-five bread wheat genotypes (G), carring Rht 8 dwarfing gene, selected from Facultative and Winter Wheat Observation Nursery for Semiarid Environments (FAWWON-SA) of International Winter Wheat Improvement Program (IWWIP) were tested across 14 environments (E) from European, Asian and African Continents during the 2011-2012 cropping season in order to detect the effects of $G, E$ and GE interaction (GEI) on plant height (PH) by means of pattern analysis (PA). It showed that Gs originated from Russia, Ukraine and IWWIP were semi-dwarf taller than those of National Bread Wheat Breeding Program of Turkey (NBWBPT). In this study, medium-tall Gs were favorable to rain-fed Es, due to the positive relationship between $\mathrm{PH}$ and grain yield. It has been suggested that ZAF01 (Bethlehem-South Africa) among 14 Es could be more suitable for phenotyping Gs for PH potential. In conclusion, Eastern European germplasm was able to adapt to almost all Es, whereas genotypes from NBWBPT were not. Therefore, the latter needs improving its adaptability to stressful Es.
\end{abstract}

Key words: Bread wheat, plant height, genotype by environment interaction

\section{INTRODUCTION}

IWWIP is a joint program between Turkey, CIMMYT and ICARDA. Its main objective is to develop winter/facultative wheat germplasm for the region of Central and West Asia. It also facilitates the winter wheat germplasm exchange for the global breeding community. Its germplasm development targets both irrigated and dryland conditions. It annually distributes nurseries to more than 100 cooperators in more than 50 countries. In addition, interested breeding programs submit their material to IWWIP for inclusion into international testing (http://www.iwwip.org).

IWWIP oftenly use parents, carring Rht (reduced height) genes, in crossing blocks for improving widely adapted Gs. The adoption of 'Norin 10' semi-dwarfing genes $R h t$-B1b (formerly $R h t 1$ ) and $R h t-\mathrm{D} 1 \mathrm{~b}$ (formerly $R h t 2$ ) was a major event in wheat breeding, making a substantial contribution to the 'Green Revolution' (Hedden, 2003). These two dwarfing genes are effective in reducing plant height and have been associated with increased wheat yields, improved lodging resistance and higher harvest indices (Worland et al., 1994; Beharav et al., 1998). But they are not beneficial in the Mediterranean environment, where high temperatures and drought are commonly encountered in the period between anthesis and grain filling (Worland et al., 2001). As a result, alternative dwarfing genes, such as the GA (gibberellic acid)sensitive $R h t 8$, have become widespread among cultivars grown in the Mediterranean basin and Southern Europe (Worland et al., 1998).

Singh et al. (2001) developed a set of near-isogenic lines in 10 modern CIMMYT bread wheat and six durum wheat backgrounds. They assessed the effect of the Rht$\mathrm{B} 1 \mathrm{~b}$ and $R h t-\mathrm{D} 1 \mathrm{~b}$ dwarfing alleles in six Es with varying levels of drought stress. Trethowan et al. (2001) studied the same germplasm and found that while the presence of a height reducing allele decreased both the coleoptile length and plant height, there was a significant genetic background effect for these traits among the different isolines relative to any height reducing alleles.

Globally distributed FAWWON-SA targets dry Es with the yield level of 1-3 t/ha. Its objective is to offer diverse germplasm for evaluation and selection of the best lines for utilization in crosses or further studies. Most of the entries in this nursery are tall with the height above $100 \mathrm{~cm}$ under the dryland conditions of Turkey. The FAWWON-SA germplasm developed by TurkeyCIMMYT-CARDA IWWIP Program is combined with the germplasm from the breeding programs in Eastern Europe, Iran, S. America, Turkey and USA which generously agreed to share their germplasm. This 
introduced germplasm is pre-screened in Turkey for adaptation to dry $\mathrm{E}$ and diseases.

PA which consists of cluster (Fox and Rosielle, 1982) and biplot (Gauch and Zobel, 1997) techniques was developed to use some of the functions of these methods jointly. The GEI information from MET (MultiEnvironment Trial) grown over diverse Es can be studied with PA (DeLacy et al, 1996; Zobel et al., 1988) to identify Gs with similar responses across Es, and to identify those Es which produce similar discriminations among the Gs growing in them. PA has been applied to many MET and shown to be very effective (Abdalla et al., 1996; Lillemo et al., 2004; Zhang et al., 2006).

Using PA, we were interested in detecting effects of GEI on PH of 25 Gs, carrying Rht 8 gene, selected from FAWWON-SA tested across 14 Es. Information gained from this study should facilitate the design of a testing and/or breeding strategy to assist in selecting superior genotypes for target growing sites.

\section{MATERIALS AND METHODS}

\section{Field trials}

Twenty-five Gs (G1-G25), including 14 advanced lines and 11 cultivars were evaluated in 14 Es representing different ecosystems and climates from Asia, Europe and Africa during 2011-2012 cropping season (Tables 1 and 2). Gs used in this study were selected from FAWWONSA based on their PH data over 14 Es. The trials were set up using alpha lattice design (Patterson and Williams, 1976) in two replications in a plot size of $2.5 \mathrm{~m}$ length, six rows with $0.2 \mathrm{~m}$ spacing between rows. Standard agronomic practices were applied as per the recommendation of each $\mathrm{E}$ in each country.

Table 1. Code, parentage, cluster and plant height values of the 25 genotypes

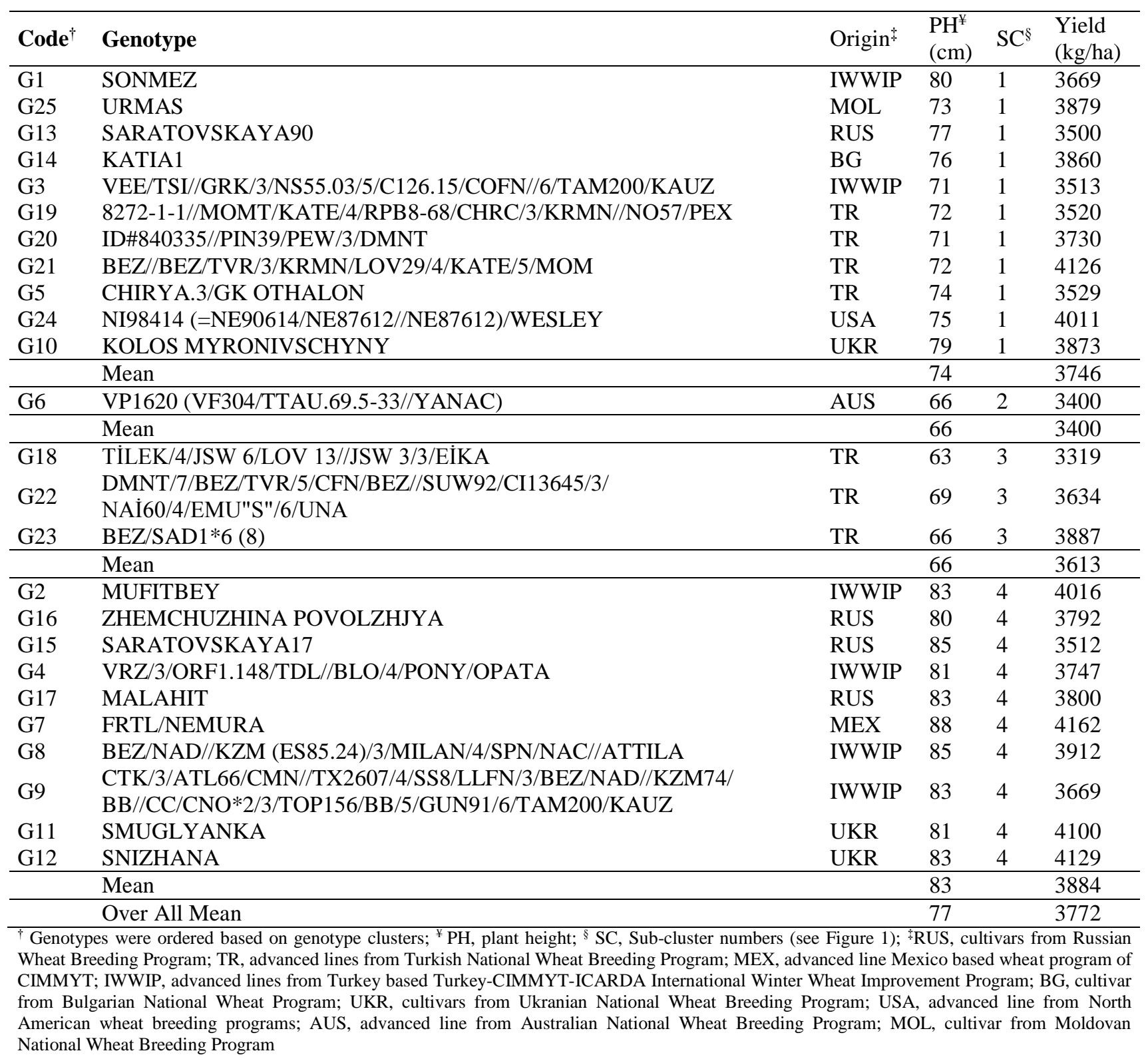


Table 2. Code, cluster, plant height values, climatic and geographical characteristics of 14 environments

\begin{tabular}{|c|c|c|c|c|c|c|c|c|c|}
\hline $\operatorname{Code}^{\dagger}$ & Country & Location & Latitude & Longitude & $\begin{array}{l}\text { Altitude } \\
\text { (masl) }\end{array}$ & Sub-Cluster & $\begin{array}{l}\text { Plant } \\
\text { Height } \\
\text { (cm) }\end{array}$ & Climate & $\begin{array}{c}\text { LTAP }^{\S} \\
(\mathbf{m m})\end{array}$ \\
\hline AFG01 & Afghanistan & Kabul & $34^{\circ} 25^{\prime} \mathrm{N}$ & $68^{\circ} 07^{\prime} \mathrm{E}$ & 1825 & 1 & 88 & $\mathrm{SA}^{\ddagger}$ & $312^{¥}$ \\
\hline AZB02 & Azerbaijan & Baku & $40^{\circ} 23^{\prime} \mathrm{N}$ & $49^{\circ} 52^{\prime} \mathrm{E}$ & -28 & 1 & 89 & SSA & $210^{¥}$ \\
\hline BUL01 & Bulgaria & Dobrich & $43^{\circ} 39^{\prime} \mathrm{N}$ & $28^{\circ} 01^{\prime} \mathrm{E}$ & 236 & 1 & 92 & $\mathrm{HC}$ & 541 \\
\hline ARM02 & Armenia & Echmiadzin & $40^{\circ} 10^{\prime} \mathrm{N}$ & $44^{\circ} 17^{\prime} \mathrm{E}$ & 853 & 1 & 85 & $\mathrm{C}$ & 301 \\
\hline ESP07 & Spain & Lleida & $41^{\circ} 63^{\prime} \mathrm{N}$ & $0^{\circ} 78^{\prime} \mathrm{E}$ & 243 & 1 & 85 & SA & 369 \\
\hline \multirow[t]{2}{*}{ SRB01 } & Serbia & Novi Sad & $45^{\circ} 3^{\prime} \mathrm{N}$ & $19^{\circ} 8^{\prime} \mathrm{E}$ & 84 & 1 & 85 & $\mathrm{HC}$ & 647 \\
\hline & Mean & & & & & & 87 & & \\
\hline \multirow[t]{2}{*}{ ZAF01 } & South Africa & Bethlehem & $28^{\circ} 16^{\prime} \mathrm{S}$ & $28^{\circ} 30^{\prime} \mathrm{E}$ & 1696 & 2 & 101 & $\mathrm{HC}$ & 680 \\
\hline & Mean & & & & & & 101 & & \\
\hline GEO03 & Georgia & Tbilisi & $41^{\circ} 43^{\prime} \mathrm{N}$ & $44^{\circ} 47^{\prime} \mathrm{E}$ & 563 & 3 & 74 & $\mathrm{C}$ & 568 \\
\hline IRN14 & Iran & Ardabil & $38^{\circ} 15^{\prime} \mathrm{N}$ & $48^{\circ} 17^{\prime} \mathrm{E}$ & 1350 & 3 & 74 & SA & $303^{¥}$ \\
\hline KAZ01 & Kazakhstan & Almaty & $43^{\circ} 24^{\prime} \mathrm{N}$ & $76^{\circ} 61^{\prime} \mathrm{E}$ & 760 & 3 & 64 & $\mathrm{HC}$ & 684 \\
\hline KAZ02 & Kazakhstan & Saryagash & $41^{\circ} 48^{\prime} \mathrm{N}$ & $69^{\circ} 35^{\prime} \mathrm{E}$ & 419 & 3 & 63 & $\mathrm{C}$ & 576 \\
\hline \multirow[t]{2}{*}{ RUS01 } & Russia & Krasnodar & $45^{\circ} 02^{\prime} \mathrm{N}$ & $38^{\circ} 95^{\prime} \mathrm{E}$ & 17 & 3 & 64 & $\mathrm{HC}$ & 735 \\
\hline & Mean & & & & & & 68 & & \\
\hline IRN11 & Iran & Maragheh & $37^{\circ} 24^{\prime} \mathrm{N}$ & $46^{\circ} 16^{\prime} \mathrm{E}$ & 1852 & 4 & 54 & $\mathrm{SA}$ & 353 \\
\hline \multirow[t]{3}{*}{ UKR04 } & Ukraine & Kharkov & $50^{\circ} 0^{\prime} \mathrm{N}$ & $36^{\circ} 13^{\prime} \mathrm{E}$ & 143 & 4 & 58 & $\mathrm{HC}$ & 517 \\
\hline & Mean & & & & & & 56 & & \\
\hline & Overall Mean & & & & & & 77 & 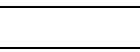 & \\
\hline
\end{tabular}

Analysis of variance (ANOVA) and pattern analysis (PA)

PH data collected from 25 Gs tested across 14 Es were used to examine the partitioning of sum of squares (SS) to G, E and GEI with the mean squares of the error. Before the application of PA, the data matrix was standardized within Es, whereby the E main effects and the grand mean are removed, with the remainder divided by the within $\mathrm{E}$ standard deviation (Fox and Rosielle, 1982; DeLacy et al., 1996). From the standardized data matrix, a squared Euclidean distance matrix (i.e. a distance matrix) was computed for Gs and Es. Hierarchical agglomerative clustering (Williams, 1976) with incremental SS (Ward, 1963 ) as the fusion criterion was applied to the matrices, i.e. in any part of the dendrogram, members or groups were joined to minimize the new within group SS (Figures 1 and 2).

The biplot derived from PCA (principal components analysis) (using $\mathrm{E}$ standardized data) assessed the relationships among Gs, among Es, and between Gs and Es (Kempton, 1984; Figure 3). The statistical software CROPSTAT, which was developed by International Rice Research Institute, was used to perform the ANOVA and PA. In order to draw visually better dendrograms, they were constructed using MINITAB while the biplot was depicted by means of Biplot and Singular Value Decomposition Macros for Excel@ (Lipkovich and Smith, 2002).

\section{Genotyping analysis for Rht 8 gene}

According to the method described by Korzun et al. (1998), genotyping analysis for Rht 8 gene was conducted at CIMMYT in Mexico.

\section{RESULTS AND DISCUSSION}

\section{ANOVA}

ANOVA indicated that the $\mathrm{E}$ main effect was the predominant significant source of variation, followed by $\mathrm{G}$ main effect and GEI. The proportion of the total sum of squares due to G, E and GEI during the 2011-2012 cropping season was 18,71 and $11 \%$ for PH. The ratio of the sum of squares due to GEI and those due to G main effect with respect to E main effect were 3.9 and 0.4 for $\mathrm{PH}$ (data not shown).

\section{Genotype and environment means}

Mean PH for Gs was $77 \mathrm{~cm}$ and varied from $66 \mathrm{~cm}$ for G18 to $88 \mathrm{~cm}$ for G7 (Table 1). Of $25 \mathrm{Gs}$, 7, from NBWBPT, were among the shortest ones. On the other hand, Gs from Russia, Ukraine and IWWIP were mostly taller than the other ones.

As for Es, PH ranged between $54 \mathrm{~cm}$ at IRN11 (Maragheh-Iran) to $101 \mathrm{~cm}$ at ZAF01 (Bethlehem-South Africa) (Table 2). On the other hand, the Es differed in amount of rainfall (Table 2), which caused contrasting growing conditions and therefore a range of $\mathrm{PH}$ under 
rainfed conditions. The annual rainfall varied from 210 for AZB02 (Baku-Azerbaijan) to $735 \mathrm{~mm}$ for RUS01 (Krasnodar-Russia). They also had adverse climatic patterns, ranging from semi-arid for AFG01 (KabulAfghanistan) to humid continental for BUL01 (DobrichBulgaria).

\section{Clustering genotypes and environments}

Applying distance level where $50 \%$ or more of the sum of squares of the GEI was retained, leads to distinguishing four sub-clusters (SC) for $\mathrm{G}$ and $\mathrm{E}$ in regard to the $\mathrm{PH}$ investigated during the 2011-2012 crop cycle (Zhang et al., 2006). This clustering resulted in an $81 \%$ reduction in data size, while retaining $85 \%$ of the sum of squares of $\mathrm{G}, 82 \%$ of sum of squares of $\mathrm{E}$ for $\mathrm{PH}$ (data not shown). The results of cluster analysis based on adjusted $\mathrm{PH}$ data from 14 Es and $25 \mathrm{Gs}$ are given in Tables 1 and 2 as well as Figures 1 and 2 .

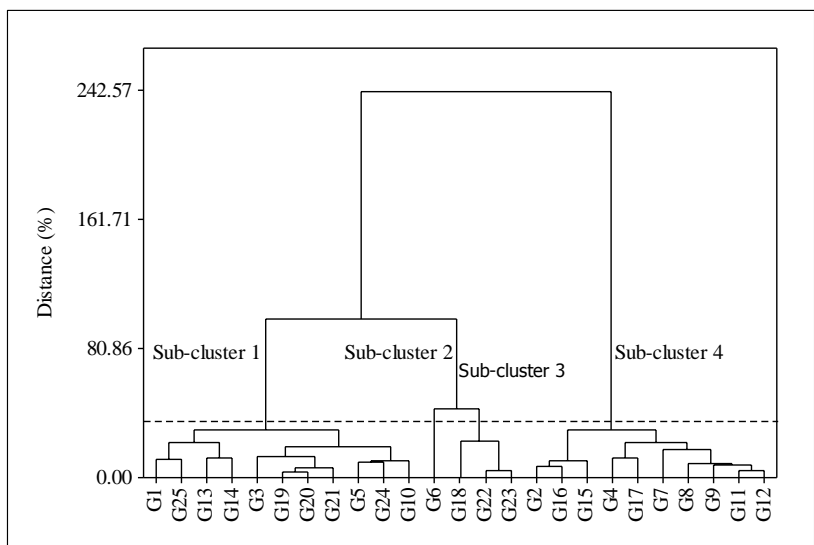

Figure 1. Dendrogram by cluster analysis conducted for plant height data obtained from 25 genotypes tested across 14 environments (For further information about genotypes, see Table 1)

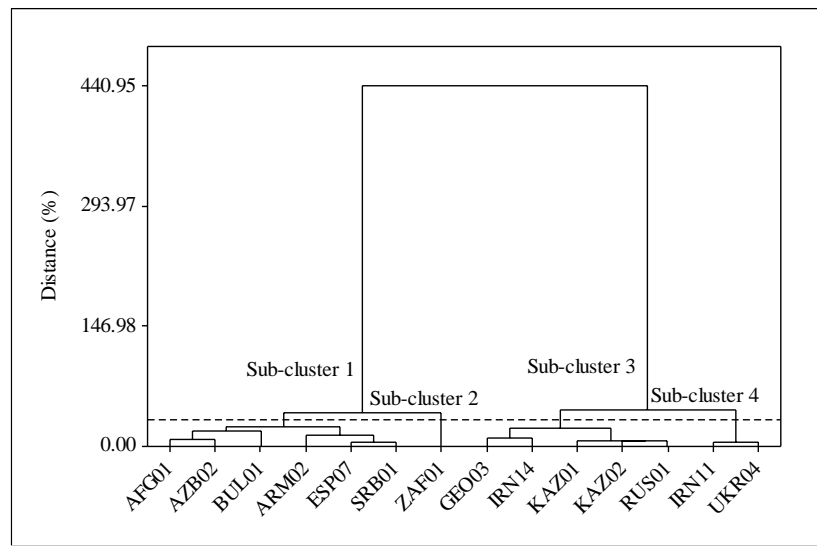

Figure 2. Dendrogram by cluster analysis conducted for plant height data collected from 14 environments (For further information about environments, see Table 2)

Considering G clustering, G1, G25, G13, G14, G3, G19, G20, G21, G5, G24 and G10, respectively, were in the first $\mathrm{SC}$, with mean of $74 \mathrm{~cm}$ in $\mathrm{PH}$, ranging from 71 to $80 \mathrm{~cm}$, but the Gs from second and third SCs were the shortest ones, with mean $66 \mathrm{~cm}$. Consequently, all Gs from SCs 1, 2 and 3 (except G1, G13 and G10) were shorter than overall mean $(77 \mathrm{~cm})$ in $\mathrm{PH}$. Interestingly, majority of the shortest Gs were from NBWBPT. The fourth SC included G2, G16, G15, G4, G17, G7, G8, G9, G11 and G12, with mean of $83 \mathrm{~cm}$ in $\mathrm{PH}$, ranging from 80 to $85 \mathrm{~cm}$. On the other hand, Gs, mostly originated from Russia, Ukraine and IWWIP, in the SC 4 were taller than those in the SCs 1, 2 and 3.

As for E clustering, AFG01, AZB02, BUL01, ARM02, ESP07 and SRB01 were in the first SC of the dendrogram (Figure 2), with mean of $87 \mathrm{~cm}$ in $\mathrm{PH}$ after $\mathrm{E}$ ZAF01, a single member of the SC 2, with mean of 101 $\mathrm{cm}$. The third SC consisted of Es GEO03, IRN14, KAZ01, KAZ02 and RUS01, with mean of $68 \mathrm{~cm}$ in PH. IRN11 and UKR04 were in the fourth SC, with mean 56 $\mathrm{cm}$ in $\mathrm{PH}$. Certainly, the first result from E clustering showed that Es in the SC 1 and 2 could be used in phenotyping Gs for determining potential $\mathrm{PH}$. The second conclusion was that Gs from NBWBPT exhibited the poor adaptation to SC 3 and 4 Es, due to Eastern European and Asian adverse climatic conditions such as Russia, Kazakhistan and Ukraine and a severe drought occurred in the Northen Iran, during the crop season of 2011-20112.

\section{Biplot analysis}

The first two principal components (PCs), which accounted for $68 \%$ of the total variation, were used for depicting the biplot (Figure 3). Gs, which were taller than the overall mean of $77 \mathrm{~cm}$, were grouped at the positive axis of the first PC, whereas Gs, which were shorter than the average, were at the negative side of the PC 1 . The biplot revealed that semi-dwarf tall Gs had similar responses across Es; however, semi-dwarf short ones differed considerably. In case of desirability of Gs for PH, the semi-dwarf tall ones should be positively selected, because PH was positively correlated with grain yield ( $r=$ $0.482 ; p<0.01)$ in this study. Accordingly it might be resulted that semi-dwarf tall Gs could be more tolerant than the semi-dwarf short ones tested across Es used in this research. As for Es, all of them were grouped at the positive axis of PC 1 (Figure 3). That all E PC1 scores are positive allows $\mathrm{PC} 1$ in the biplot to be interpreted as representing proportional $\mathrm{G}$ differences across Es, which leads to a non-crossover GE interaction (Yan et al., 2000). In other words, $\mathrm{G}$ rankings based on $\mathrm{PH}$ were not mostly changed across Es.

Adjacent Es cause similar discrimination among the Gs. Both all Gs, which were taller than the average G (77 $\mathrm{cm}$ ), and Es were located at the positive axis of PC 1 (Figure 3). This showed that semi-dwarf tall Gs generally were adaptable to almost all Es used in the study. The only AFG01 was separated from the Es, due to the fact that $\mathrm{G}$ ranking for $\mathrm{PH}$ in this $\mathrm{E}$ could be different from those in the rest of Es. 


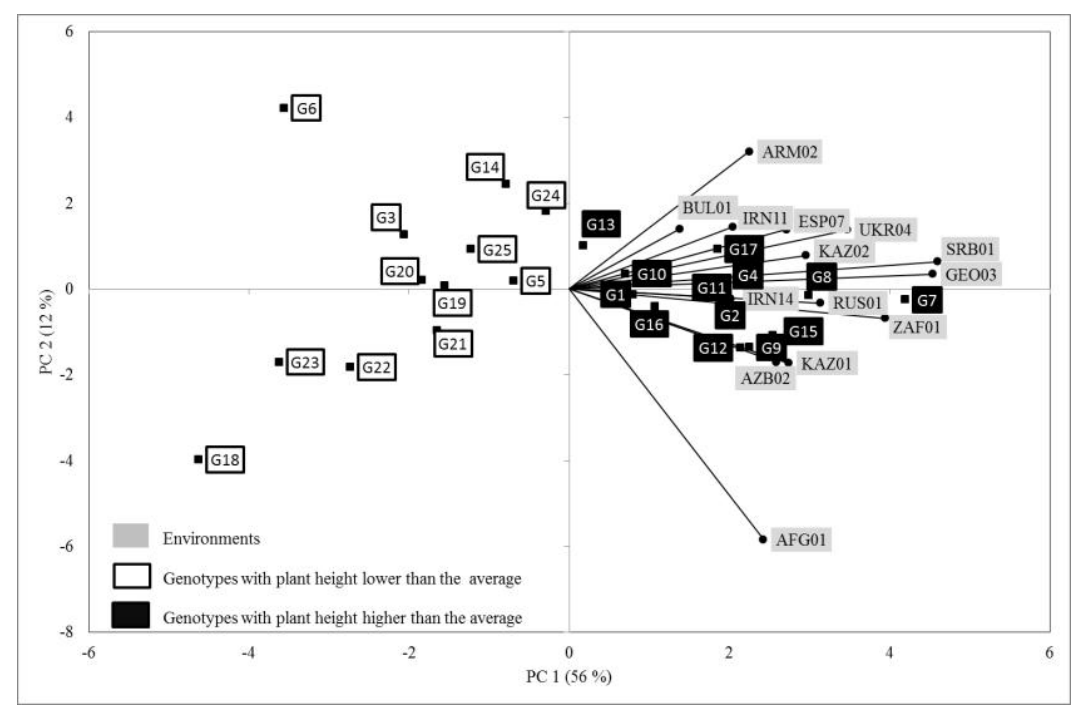

Figure 3. Biplot by Principal Components Analysis conducted for plant height data obtained from 25 genotypes tested across 14 environments (For further information about genotypes and environments, see Tables 1 and 2, respectively)

The rapid global spread of the Rht-B1b and Rht-D1b dwarfing alleles during the Green Revolution allowed wheat breeders to improve wheat with less risk of lodging. Hence, improvements in yield, quality, and disease resistance have, in general, been made in the presence of one of these dwarfing alleles. However, tall varieties may be desirable for reasons other than high yield, including high biomass and longer straw lengths. The longer coleoptiles and larger root systems of tall cultivars compared with the semidwarfs likely contributes to their relative adaptation to dry Es, where deep sowing ensures contact with available soil moisture (Rebetzke and Richards, 2000; Trethowan et al., 2001). However, other studies have proposed breeding "tall dwarfs" for adaptation to dry Es (Borrner et al., 1993; Budak et al., 1995).

One of the winter/facultative wheat breeding goals of the IWWIP is to develop Gs carring Rht 8 for where drought and heat stress occur predominantly. Worland and Law (1985) reported that the distribution of GAinsensitive dwarfing genes (Rht-B1b and Rht-D1b) is restricted to areas where heat and drought stress condition prevails during grain filling. Ellis et al. (2005) have suggested that both Rht-1 dwarfing alleles (Rht-B1b and $R h t$-D1b) also negatively affect the growth of young plants, but that this effect is not mirrored by Rht- 8 . Therefore, Rht-8 might be more suitable in reducing final plant height, without compromising early plant growth (Ellis et al., 2005).

Currently used Gs were distributed across the facultative/winter wheat Es to test them under the FAWWON-SA. Test Es varied widely for levels of precipitation, latitudes ranging from 28.16'S (South Africa) to $50^{\circ} 0$ ' N (Ukraine) and altitudes from $-28 \mathrm{~m}$ (Azerbaijan) to $1852 \mathrm{~m}$ (Iran). Even if Es differed in their geographical and climatic characteristics, E discrimination by cluster analysis was materialized only based on $\mathrm{PH}$, because of lack of the soil and climate data availability for each E. It was shown that currently available $\mathrm{E}$ data were irrelevant in clustering Es considering results of analyses conducted between spatial (e.g. environmental) and phenotypic (e.g. PH) data. But, it is obvious that the more spatial data, including soil and seasonal climatic observations and measurements, should help the more precise discrimination in clustering of Es.

Russian wheat cultivar 'Bezostaya-1' is used in crossing blocks as a source for $R h t-8$ gene in IWWIP, for improving quality as well. Indeed, Bezostaya-1 contains Japanese Aka Komugi in its pedigree, well known as the ancestor for Rht 8 gene (Worland et al., 1998). All of the Gs used in this research carry $R h t-8$ gene possibly due to Bezostaya-1 existing in their pedigrees.

Averaged over all Es, the Rht-8 containing Gs, which were originated from Russia, Ukraine and IWWIP, consistently were taller (about $10 \mathrm{~cm}$ ) than the other ones. On the orher hand, Gs selected from NBWBPT to IWWIP showed poor adaptability to almost all Es. To eliminate the poor adaption genes from the Turkish materials, frequency of $R h t-8$ gene should be increased because it was rare $(26 \%)$ in Turkish germplasm, comparing with that in Italian $(60 \%)$ and Yugoslavian $(86 \%)$ wheat (Guedira et al., 2010; Yediay et al., 2011). In the Mediterranean and South-east Anatolian regions of Turkey, where heat and drought stresses are common place from anthesis onwards and especially during grain filling, since the GA-insensitive Rht-1 dwarfing genes are not well adapted to these conditions, $R h t-8$ would be a valuable resource for Turkish wheat breeding (Yediay et al., 2011).

We also recommend that $1 \mathrm{BL} .1 \mathrm{RS}$ wheat-rye translocations should be used in Turkish wheat breeding program to enhance the adaptation to stressful Es. It is well documented that 1BL.1RS wheat-rye translocations are useful, because of their positive agronomic traits including yield performance, yield stability, wide adaptation and stress tolerance (Rajaram et al., 1983; Villareal et al., 1991; Waines and Ehdaie, 2007). Yediay et al. (2010) have screened 107 wheat Gs, including 
durum and bread wheat cultivars and landraces from Turkey using six rye-specific DNA markers. It has been revealed that only four Turkish bread wheat cultivars carry the 1BL.1RS wheat-rye translocations. Comparing the 1BL.1RS translocation frequencies in wheat cultivars from Turkey with the frequencies found in USA, China, Bulgaria and Hungary shows that Turkish wheat breeding program has not yet exploited these 1RS resources comprehensively. Taken together, the results of this study and the results presented from Altintas et al. (2007) suggest the need of broadening the genetic base of Turkish wheat breeding material, using alternative sources in crossing programs. A more precise knowledge of the genetic background of the breeding stock will contribute greatly to the creation of new populations with boarder genetic basis (Yediay et al., 2010).

There is something else about wheat stature. Straw per se could be more important than its manipulating genes for some reason. In order to better understand one of the reasons why Turkish wheat Gs were able to poorly adapt to Es, it should be taken into accout that wheat cropping in semi-arid areas of West Asia and North Africa is frequently integrated into a cereal-livestock farming system. The wheat straw, mostly used for feeding animals, represents an important commodity, its average sale price per unit weight being not less than $40 \%$ of that of grain. Therefore, modern, short-stature wheat Gs are not mostly accepted by dryland farmers because of their low straw yield (Annicchiarico and Pecetti, 2003).

We took the messages from this study given below:

1. PA was an efficient method for detecting effects of GEI on PH. It successfully discriminated semi-dwarf tall Gs vs. semi-dwarf short ones and also favorable Es vs. unfavorable ones based on PH data collected from METs.

2. Gs originated from Russia, Ukraine and IWWIP program were mostly medim tall, indicating that they might be recommended for IWWIP mandate region, Central and West Asia, because of positive correlation between $\mathrm{PH}$ and grain yield.

3. Genoypes selected from NBWBPT showed poor adaptation to almost all Es. Accordingly, Turkish germplasm can be enriched using Gs carring Rht genes and rye translocations in crossing blocks to accelerate its adaptability to stressful Es.

\section{ACKNOWLEDGMENTS}

We sincerely acknowledge all the international cooperators for proper handling of trials and data submission on regular basis.

\section{LITERATURE CITED}

Abdalla, O.S., J. Crossa, E. Autrique and I.H. DeLacy. 1996. Relationships among international testing sites of spring durum wheat. Crop Science 36: 33-40.

Altintas, S., F. Toklu, S. Kafkas, B. Kilian, A. Brandolini and H. Ozkan. 2008. Estimating genetic diversity in durum and bread wheat cultivars from Turkey using AFLP and SAMPL markers. Plant Breeding 127: 9-14.
Annicchiarico, P and L. Pecetti. 2003. Developing a tall durum wheat plant type for semi-arid, Mediterranean cereallivestock farming systems. Field Crops Research 80 (2): 157-164

Beharav, A., A. Cahaner and M.J. Pinthus. 1998. Genetic correlations between culmlength, grain yield and seedling elongation within tall (rht1) and semi-dwarf (Rht1) spring wheat (Triticum aestivum L.). European Journal of Agronomy 9: 35-40.

Borner, A., A.J. Worland, J. Plaschke, E. Schumann and C.N. Law. 1993. Pleiotropic effects of genes for reduced height $(R h t)$ and day-length insensitivity $(P p d)$ on yield and its components for wheat grown in middle Europe. Plant Breeding 111: 204-216.

Budak, N., P.S. Baenziger, K.M. Eskridge, D. Baltensperger and B. Moreno-Sevilla. 1995. Plant height response of semidwarf and nonsemidwarf wheats to the environment. Crop Science 35: 447-451.

DeLacy, I.H., K.E. Basford, M. Cooper, J.K. Bull and C.G. McLaren. 1996. Analysis of multi-environment trials-an historical perspective. In: Plant adaptation and crop improvement (Cooper M, Hammer GL, eds.). CAB International (UK), pp: 39-124.

Ellis, M.H., G.J. Rebetzke, F. Azanza, R.A. Richards and W. Spielmeyer. 2005. Molecular mapping of gibberellinresponsive dwarfingdwarfing genes in bread wheat. Theoretical and Applied Genetics 111: 423-430.

Fox, P.N. and A.A. Rosielle. 1982. Reducing the influence of environmental main-effects on pattern analysis of plant breeding environments. Euphytica 31: 645-656.

Gauch, H.G. and R.W. Zobel. 1997. Identifying megaenvironments and targeting genotypes. Crop Science 37: 311-326.

Guedira, M., G. Brown-Guedira, D. van Sanford, C. Sneller, E. Souza and D. Marshall. 2010. Distribution of Rht genes in modern and historic winter wheat cultivar from the Eastern and Central USA. Crop Science 50: 1811-1822.

Hedden, P. 2003. The genes of the green revolution. Trends in Genetics 19: 5-9.

Kempton, R.A. 1984. The use of bi-plots in interpreting varietyby-environment interactions. Journal of Agricultural Science 103: 123-135.

Korzun, V., M.S. Roder, M.W. Ganal, A.J. Worland and C.N. Law. 1998. Genetic analysis of the dwarfing gene (Rht8) in wheat. Part I. Molecular mapping of Rht8 on the short arm of chromosome 2D of bread wheat (Triticum aestivum L.). Theoretical and Applied Genetics 96: 1104-1109.

Lillemo, M., M. van Ginkel, M.R. Trethowan, E. Hernandez and S. Rajaram. 2004. Associations among international CIMMYT bread wheat yield testing locations in high rainfall areas and their implications for wheat breeding. Crop Science 44: 1163-1169.

Lipkovich, I.A. and E.P. Smith. 2002. Biplot and Singular Value Decomposition Macros for ExcelC. Journal of Statistical Software 7(5): 1-15.

Patterson, H.D. and E.R. Williams. 1976. A class of resolvable incomplete block designs. Biometrika 63: 83-92.

Rajaram, S., C. Mann, G. Ortiz-Ferrara and A. Mujeeb-Kazi. 1983. Adaptation, stability and high yield potential of certain 1B/1R CIMMYT Wheats. Proc 6th international wheat genetics symposium, Kyoto (Japan), pp: 613-621.

Rebetzke, G.J. and R.A. Richards. 2000. Gibberilic acidsensitive dwarfing genes reduce plant height to increase kernel number and grain yield of wheat. Australian Journal of Agricultural Research 51: 235-245. 
Singh, R.P. J. Huerta-Espino, S. Rajaram and J. Crossa. 2001. Grain yield and other traits of tall and dwarf isolines of modern bread and durum wheats. Euphytica 119: 241-244.

Trethowan, R.M., R.P. Singh, J. Huerta-Espino, J. Crossa and M. van Ginkel. 2001. Coleoptile length of near isogenic Rht lines of modern CIMMYT bread and durum wheats. Field Crops Research 70: 167-176.

Villareal, R.L., S. Rajaram, A. Mujeeb-Kazi and E. del Toro. 1991. The effects of chromosome 1B/1R translocation on yield potential of certain spring wheats (Triticum aestivum L.). Plant Breeding 106: 77-81.

Waines, J.G. and B. Ehdaie. 2007. Domestication and crop physiology: roots of green-revolution wheat. Annals of Botany 100(5): 991-998.

Ward, J.H. 1963. Hierarchical grouping to optimize an objective function. Journal of the American Statistical Association 58: 236-244.

Williams, W.T. 1976. Pattern analysis in agricultural science. Elsevier Scientific Publishing Company, Amsterdam, The Netherlands.

Worland, A.J., V. Korzun, M.S. Roder, M.W. Ganal and C.N. Law. 1998. Genetic analysis of the dwarfing gene Rht-8 in wheat. Part II. The distribution and adaptive significance of allelic variants at the $R h t-8$ locus of wheat as revealed by microsatellite screening. Theoretical and Applied Genetics 96: 1110-1120.

Worland, A.J. and C.N. Law. 1985. An effect of temperature on the fertility of wheats containing the dwarfing genes Rht1,
Rht2, and Rht3. Annual Report, Cambridge, Plant Breeding Institute (UK), pp: 69-71.

Worland, A.J., E.J. Sayers and A. Borner. 1994. The genetics and breeding potential of Rht12, a dominant dwarfing gene in wheat. Plant Breeding 113: 187-196.

Worland, A.J., E.J. Sayers and V. Korzun. 2001. Allelic variation at the dwarfing gene Rht8 locus and its significance in international breeding programmes. Euphytica 119: 150155.

Yan, W.K., L.A. Hunt, Q.L. Sheng and Z. Szlavnics. 2000. Cultivar evaluation and mega-environment investigation based on the GGE biplot. Crop Science 40: 597-605.

Yediay, F.E., E.E. Adeden, F.S. Baloch, A. Borner, B. Kilian and H. Ozkan. 2011. The allelic state at the major semi-dwarfing genes in a panel of Turkish bread wheat cultivars and landraces. Plant Genet Resources 9: 423-429.

Yediay, F.E., F.S. Baloch, B. Kilian and H. Ozkan. 2010. Testing of rye-specific markers located on 1RS chromosome and distribution of 1AL.RS and 1BL.RS translocations in Turkish wheat (T. aestivum L. and T. durum Desf.) varieties and landraces. Genetic Resources and Crop Evolution 57: 119-129.

Zhang, Y., Z.H. He, A.M. Zhang, M. van Ginkel and G.Y. Ye. 2006. Pattern analysis on grain yield of Chinese and CIMMYT spring wheat cultivars grown in China and CIMMYT. Euphytica 147: 409-420.

Zobel, R.W., M.G. Wright and H.G. Gauch. 1988. Statistical analysis of yield trial. Agronomy Journal 80: 388-393. 